\title{
Multiple microcrystal deposition disease in a patient with systemic lupus erythematosus
}

\author{
MARTÍN A. RODRÍGUEZ, HERNANDO PAUL, ISAAC ABADí, \\ JOSÉ R. BRAVO, AND PEDRO ARMAS \\ From the National Center for Rheumatic Diseases and the Department of Medicine, Hospital Universitario, \\ Apartado 5495, Caracas 1010, Venezuela
}

SUMMARY A 17-year-old female patient with systemic lupus erythematosus (SLE) developed chronic tophaceous gout, chondrocalcinosis and articular capsule calcification in several joints. Analysis of synovial fluid and tophi revealed the coexistence of monosodium urate, calcium pyrophosphate, hydroxyapatite, and cholesterol crystals.

Despite the high frequency of arthritis and soft tissue calcification in systemic lupus erythematosus (SLE) ${ }^{1-4}$ only few cases of crystal-induced synovitis have been recognised in this disease. Talbott and $\mathrm{Yu}$ reported the first case of coexisting gout and SLE in $1976 .{ }^{5}$ Since then only few cases have been described.$^{6-9}$ Recently microcrystalline uric acid, calcium pyrophosphate dihydrate (CPPD), and hydroxyapatite crystals were found in synovial fluid from an SLE patient with acute synovitis, ${ }^{10}$ but so far cholesterol crystals have not been reported in this disease.

It is the purpose of this communication to report a very unusual case of a young female patient with SLE who developed chronic tophaceous gout, chondrocalcinosis, and articular capsule calcification in several joints. Analysis of synovial fluid showed monosodium urate (MSU) and CPPD crystals. Material extruded from tophi revealed MSU and cholesterol crystals. Apatite crystals were suspected on a clinical basis.

\section{Case report}

A 17-year-old female patient was first seen in November 1971 because of polyarthralgia, malar, rash, anasarca, asthenia, and high blood pressure. She denied a past history of drugs. Laboratory tests

Accepted for publication 19 August 1983.

Correspondence to Dr Martín A. Rodríguez, National Center for Rheumatic Diseases, Hospital Universitario, Apartado 5495, Caracas 1010, Venezuela. revealed leucopenia, reticulocyte cell count $4 \cdot 2 \%$, positive direct and indirect Coomb's test, false positive serological test for syphilis (confirmed by Treponema pallidum immobilisation test), positive LE cells, positive fluorescent antinuclear antibodies (FANA) test (diffuse pattern), anti-DNA 12.1\% (normal range $<5 \%$ ), $\mathrm{CH}_{50} 111 \mathrm{U} / \mathrm{ml}$ (normal range 150-250), hyaline and granular casts and red blood cells in the urine sediment, urinary protein excretion $1.8 \mathrm{~g} / 24 \mathrm{~h}$, and creatinine clearance $64 \mathrm{ml} / \mathrm{min}$. A renal biopsy revealed proliferative glomerulonephritis with some epithelial crescents. A diagnosis of SLE was established, and treatment was initiated with prednisone $50 \mathrm{mg}$, frusemide $80 \mathrm{mg}$, and spironolactone $25 \mathrm{mg}$. In February 1972 she had episodes of convulsions, abnormal behaviour, haemoptysis, and chest pain. A chest $x$-ray showed cotton-wool-like infiltrates and pleural effusion. At that time she was on prednisone $30 \mathrm{mg} /$ day, and was started on azathioprine $100 \mathrm{mg}$ daily with good response. In August 1972 she began complaining of swelling in the left knee, wrists, metacarpophalangeal (MCP) and proximal interphalangeal (PIP) joints, which was successfully controlled with indomethacin.

In 1976 subcutaneous nodules were detected over the extensor surface of elbows, right knee, and MCP and PIP joints of the left middle finger. $X$-ray studies showed soft-tissue thickening, articular capsule calcification of several MCP and PIP joints (Fig. 1), fluffy calcification in the triangular ligament of the left wrist (Fig. 2), and linear calcification in both knees. Laboratory tests revealed serum uric acid 12 


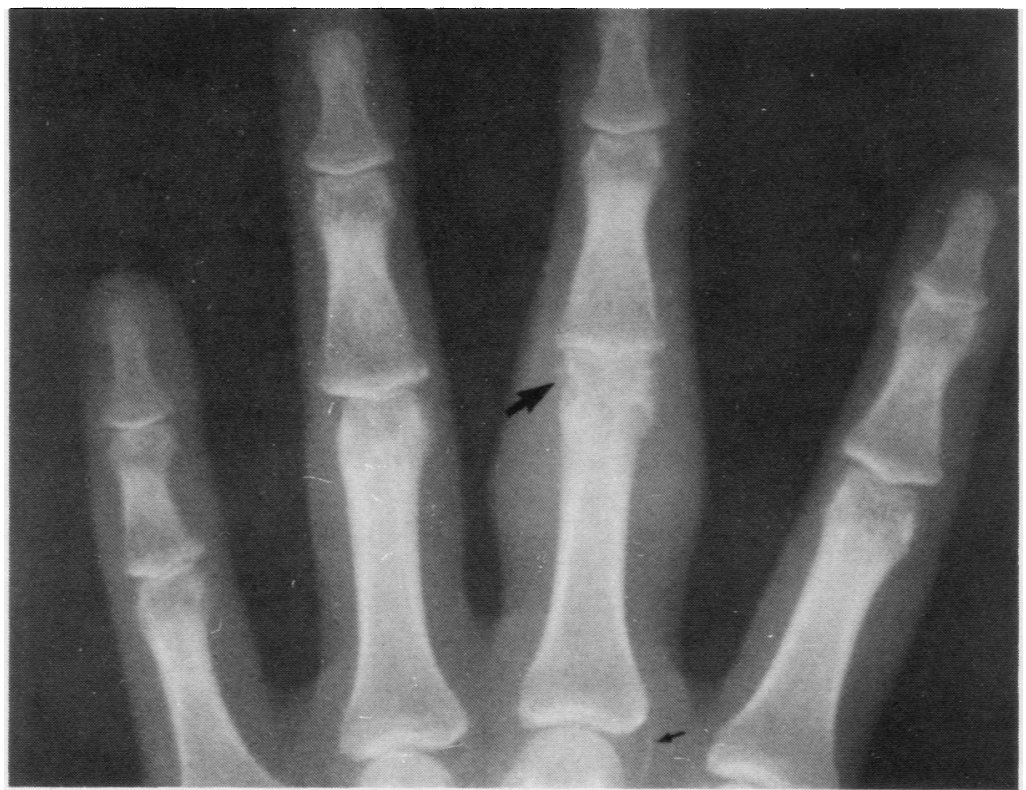

Fig. 1 Soft-tissue thickening of PIP middle finger and articular capsule calcification of several $M C P$ and PIP joints (arrow) in left hand.

$\mathrm{mg} / \mathrm{dl}(0.7 \mathrm{mmol} / \mathrm{l})$, uricosuria $520 \mathrm{mg} / 24 \mathrm{~h}$, and serum parathormone (PTH) $19 \mu \mathrm{Eq} / \mathrm{ml}$ (normal range 2-10). A whitish paste-like material was obtained from an MCP joint nodule revealing abundant needle and rod-shaped crystals with strong negative birefringence on polarised light microscopy. A diagnosis of tophaceous gout was established, and allopurinol started at $300 \mathrm{mg} /$ day.

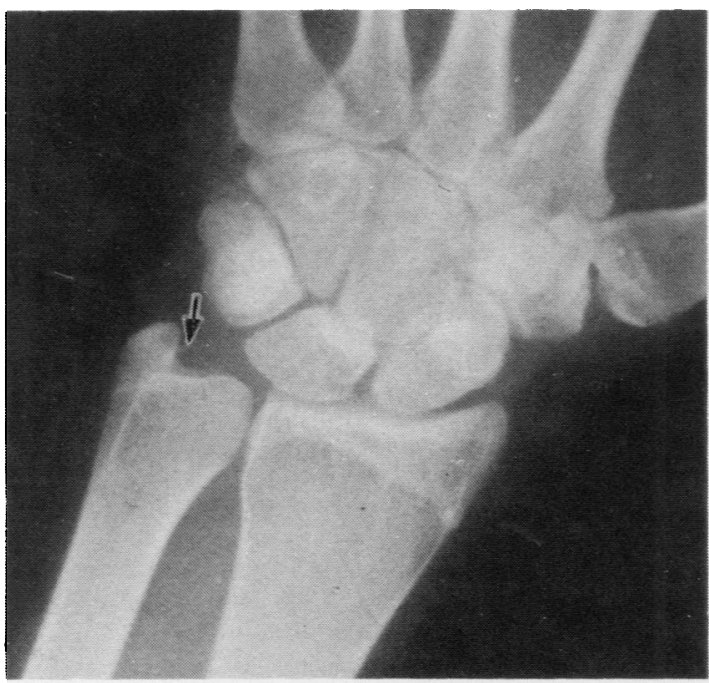

Fig. 2 Calcification in the triangular ligament of the left wrist.
During the last few years several acute inflammatory bouts have been superimposed on chronic articular manifestations, whereas SLE related symptoms have remained quiescent. In 1981 she was put on maintenance dialysis because of end-stage renal failure. Recent laboratory tests revealed serum uric acid $7.7 \mathrm{mg} / \mathrm{dl}(0.46 \mathrm{mmol} / \mathrm{l})$, uricosuria $160 \mathrm{mg} / 24 \mathrm{~h}$, proteinuria $2.6 \mathrm{~g} / 24 \mathrm{~h}$, creatinine clearance $8 \mathrm{ml} / \mathrm{min}$, serum phosphate $5.9 \mathrm{mg} / \mathrm{dl}$, serum calcium $9.5 \mathrm{mg} / \mathrm{dl}$ ( $2.4 \mathrm{mmol} / \mathrm{l})$, serum PTH $30 \mu \mathrm{Eq} / \mathrm{ml}$, and serum lipid profile within normal limits. She denied joint disease or known hyperuricaemia among her firstdegree relatives, and levels of serum uric acid in her mother and 3 siblings were normal.

\section{SYNOVIAL FLUID}

Synovial fluid obtained from the left ankle in June 19.78 showed a mildly inflammatory fluid with reduced viscosity, poor mucin clot, and leucocytes $8.700 \times 10^{9} / 1$. Abundant needle and rod shaped crystals with strong negative birefringence, suggestive of MSU crystals, were found on a wet preparation examined by compensated polarised light microscopy.

A drop of synovial fluid obtained from the PIP joint of the left middle finger in April 1981 revealed strongly negative birefringent needle shaped crystals, suggestive of MSU, and weakly positive birefringent rod shaped crystals suggestive of CPPD. Amorphous material and rod shaped crystals were strongly positive when stained with $2 \%$ alizarin red used as a rapid 


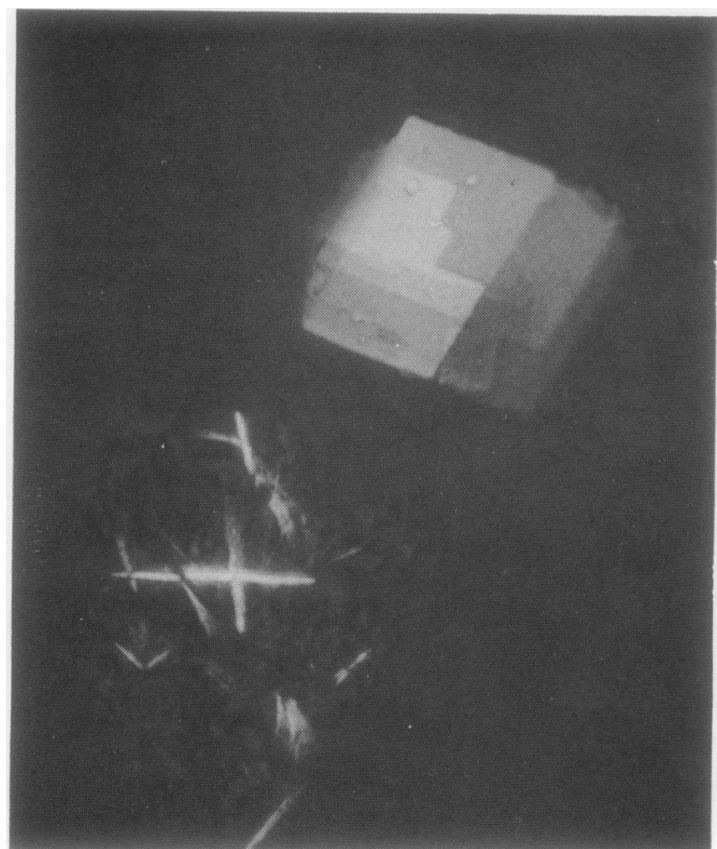

Fig. 3 Strongly negative bire fringent needle-shaped crystals (MSU) and plate-like crystals with notched corners (cholesterol) found simultaneously in a tophus overlying the left knee.

screening test to detect calcium phosphate compounds. ${ }^{11}$

TO P H I

Polarised light microscopy. Specimens obtained surgically from a tophus overlying the left knee, and

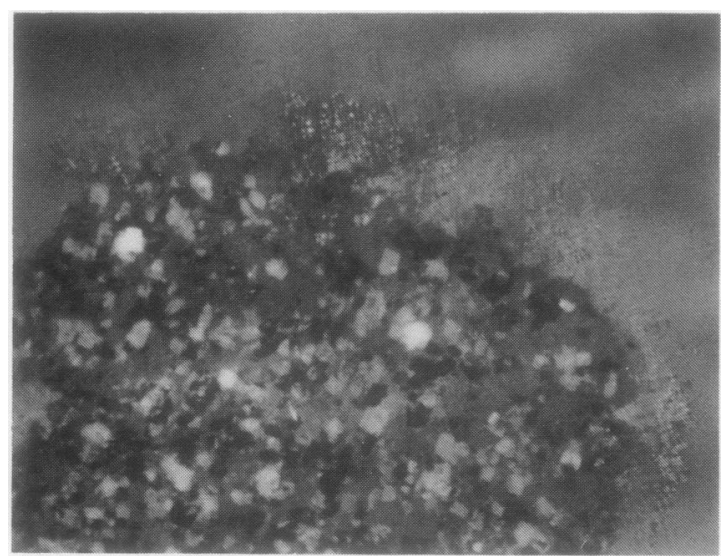

Fig. 4 Disappearance of needle shaped (MSU) and persistence of plate-like (cholesterol) crystals after uricase treatment of material similar to that shown in Fig. 3. material obtained from a nodule on the second MTP joint both revealed strongly negative birefringent needle shaped crystals, and large square and rectangular plate-like crystals with notched corners, suggestive of cholesterol (Fig. 3).

Uricase digestion test. A part of a purified suspension of uricase (Sigma Chemical Co.) was added to 10 parts of material obtained from tophi, followed by incubation at $25^{\circ} \mathrm{C}$ for $2 \mathrm{~h}$ at $\mathrm{pH} 8.5$. The needle and rod shaped crystals disappeared, while the platelike crystals remained unaltered (Fig. 4).

Electron microscopy. One drop of tophus material was promptly placed on a clean glass slide. Six Formvar coated EM grids were floated on the drop for $10 \mathrm{~s}$. The grids were then air dried and examined unstained in a Zeiss EM 10 TEM with a $60 \mathrm{kV}$ beam. The needle and rod shaped crystals exhibited the characteristic ultrastructure of MSU crystals. ${ }^{12}$

$\mathrm{X}$-ray diffraction analysis. Chalky material obtained from tophi was treated with 2 drops of lyophilised hyaluronidase for 15 minutes at $20^{\circ} \mathrm{C}$. After centrifugation for $20 \mathrm{~min}$ at $2500 \mathrm{rpm}, 5 \mathrm{ml}$ of $1 \%$ solution of 1:50 trypsin in deionised water was added to the residue, followed by incubation for $4 \mathrm{~h}$ at $37^{\circ} \mathrm{C}^{13}$ The sediment was washed twice in saline and centrifuged at $2500 \mathrm{rpm}$ for $10 \mathrm{~min}$. The resulting sediment was then dried in an oven at $130^{\circ} \mathrm{C}$ for $30 \mathrm{~min}$, and studied by $x$-ray diffraction with a Debbye-Scherrer power camera (North American Phillips) of $114.6 \mathrm{~mm}$ diameter using chromium K alpha radiation with a vanadium filter. Measurements were based on wavelength $0.229092 \mathrm{~nm}$. The specimens were exposed for $20 \mathrm{~h}$ at $60 \mathrm{kV}$ and 20 $\mathrm{mA}$. The patterns were characteristic of MSU and cholesterol crystals.

\section{Discussion}

Whereas athralgia and nondeforming arthritis are very common, only a few cases of crystal-induced synovitis have been recognised in SLE patients. To our knowledge this is the first case with articular manifestations due to concurrent deposition of MSU, CPPD, hydroxyapatite and cholesterol crystals. Although MSU, CPPD, and hydroxyapatite crystals have been previously identified in association with SLE, ${ }^{4-10}$ so far as we know cholesterol crystals have not been described before. Ryan et al. observed a lipid laden effusion in SLE, but did not report the presence of cholesterol crystals. ${ }^{14}$ These crystals have been identified in synovial fluid from patients with rheumatoid arthritis and other rheumatic conditions. ${ }^{15-17}$

MSU crystals were identified in our patient by their typical strongly negative birefringence on polarised 
light microscopy, a positive uricase test, and characteristic $x$-ray diffraction pattern. ${ }^{18}$ Some precipitating factors might be considered as explaining the development of gout in this patient. She was on diuretics and prednisone and had renal failure with increased serum PTH levels. Diuretics are a well known cause of hyperuricaemia and secondary gout, ${ }^{19}$ and Schumacher has suggested that corticosteroid therapy might predispose to unusual MSU crystal collections. ${ }^{20}$ Impairment of renal function may also contribute to hyperuricaemia,${ }^{21}$ and high levels of uric acid have been recognised in hyperparathyroidism..$^{22}$ Thus it seems likely that the MSU crystal deposition resulted from a combination of several factors in our patient.

Our radiological finding of chrondrocalcinosis in knees and wrists, and calcification around MCP and PIP joints in both hands is also interesting. Similar features have been described in mixed connective tissue disease, overlap syndromes, primary hyperparathyroidism, and chronic renal failure treated with periodic haemodialysis. ${ }^{1-423-28}$ However, our patient does not have the clinical criteria for any associated collagen tissue disease, and evidence of multiple crystal deposition antedated by several years her current dialysis programme. On the other hand, although the relationship between primary hyperparathyroidism and articular calcification is well established ${ }^{22}$ we are unaware of any previous report concerning the coexistence of CPPD crystal deposition and secondary hyperparathyroidism. Thus our finding of CPPD-like crystals is intriguing. They might represent apatite crystals or other calcium phosphate compounds as suggested by the alizarin red stain. ${ }^{11}$ Rod shaped clumps of apatite, which may be mistaken for CPPD, have been described previously. ${ }^{29}$ Nonetheless, because of the small amount of MCP joint fluid obtained, crystals could not be further analysed, and therefore we could only suspect but not confirm CPPD crystals.

The presence of cholesterol crystals within the tophi in this patient is also interesting. Lichestein $e t$ al. described lipid material containing tophi, ${ }^{30}$ and Ryan $e t$ al. reported lipid laden effusions in patients with SLE, ${ }^{14}$ but these authors did not describe cholesterol crystals. Recently Reginato et al. have described acute monoarthritis associated with lipid microspherules, ${ }^{31}$ the significance of which remains unclear. Since our patient did not have systemic lipid abnormalities, and cholesterol crystals were found within the tophi but not in synovial fluid, we assume that local factors, such as release of lipids due to tissue breakdown, may have been responsible for cholesterol crystal formation.

The increasing number of reports on the coexistence of gout and SLE and on multiple crystal deposi- tion suggest that there is some underlying common predisposition to crystal formation in the connective tissue of these patients. This report illustrates the complexity of such cases and the need to rule out other aetiologies during articular flare-ups in patients with SLE.

We are grateful to Dr Ralph H. Schumacher and Dr Antonio Reginato for critical revision of this paper. We are also indebted to Dr Henry Katz, University of Pennsylvania, for performing $x$-ray diffraction studies.

\section{References}

1 Moskowitz R W, Katz D. Chondrocalcinosis coincidental to other rheumatic diseases. Arch Intern Med 1965; 115: 680-3.

2 Kabir D I, Malinson F D. Systemic lupus erythematosus and calcinosis cutis. Arch Dermatol 1969; 100: 17-22.

3 Quismorio F P, Dubois E L, Chandor S B. Soft-tissue calcification in systemic lupus erythematosus. Arch Dermatol 1975; 111: 352-7.

4 Budin J A, Feldman F. Soft-tissue calcification in systemic lupus erythematosus. $A J R$ 1975; 124: 358-64.

5 Talbott J H, Yu T F. Gout and uric acid metabolism. New York: Stratton Intercontinental, 1976: 205-24.

6 Moidel R A, Good A E. Coexistent gout and systemic lupus erythematosus. Arthritis Rheum 1981; 24: 969-71.

7 Wall B A, Agudelo C A, Weinblaff M E, Turner R A. Acute gout and systemic lupus erythematosus. Report of two cases and literature review.J Rheumatol 1982; 9: 305-7.

8 Lally E V, Schmidt Parker V, Kaplan S R. Acute gouty arthritis and systemic lupus erythematosus. J Rheumatol 1982; 9: 308-10.

9 Schoepflin G S, Bagdy G C. A patient with tophaceous gout and systemic lupus erythematosus associated with $\mathrm{T}$ lymphocytemediated leukopenia. Rev Rhum Mal Osteoartic 1981; special issue: $\mathbf{8 1 0}$ (abstr).

10 Rose E P, Alves L E. Coexisting gout and systemic lupus erythematosus. Arthritis Rheum 1982; 25: 713-4.

11 Paul H, Reginato A, Schumacher H R. Alizarin red S staining as a screening test to detect calcium compounds in synovial fluid. Arthritis Rheum 1983; 26: 191-200.

12 Paul H, Reginato A, Schumacher H R. Morphological characteristics of monosodium urate: a transmission electron microscopic study of intact natural and synthetic crystals. Ann Rheum Dis 1983; 42: 75-81.

13 Kohn N N, Hughes R E, McCarty D J, Faires J S. The significance of calcium phosphate crystals in the synovial fluid of arthritic patients: the pseudogout syndrome II. Identification of crystals. Ann Intern Med 1962; 56: 738-45.

14 Ryan W G, Ellefson R D, Ward L E. Lipid synovial effusions. Unique occurrence in systemic lupus erythematosus. Arthritis Rheum 1973; 16: 759-64.

15 Nye W H, Terry R, Rosenbaum D L. Two forms of crystalline lipid in cholesterol effusions. Am J Clin Pathol 1968; 49: 718-28.

16 Ettlinger R E, Hunder G G. Synovial effusions containing cholesterol crystals. Report of 12 patients and review. Mayo Clin Proc 1979; 54: 366-74.

17 Fam A G, Pritzker K P K, Cheng P T, Little A H. Cholesterol crystals in osteoarthritic joint effusions. $J$ Rheumatol 1981; 8: 273-80.

18 Howell R R, Eanes E D, Seegmiller J E. $X$-ray diffraction studies of the tophaceous deposits in gout. Arthritis Rheum 1963; 6: 97-103.

19 Paulus H E, Coutts A, Calabro J J, Klinenberg J R. Clinical significance of hyperuricemia in rout inely screened hospitalized men. JAMA 1970; 211: 277-81. 
20 Schumacher H R. Bullous tophi in gout. Ann Rheum Dis 1977; 36: 91-3.

21 Sarre $\mathrm{H}$. Congress International de la Goutte et de la lithiase urique. Evian, France, 1964.

22 Newcombe D S. Endocrinopathies and uric acid metabolism. Semin Arthritis Rheum 1973; 2: 281-300.

23 Bunch T W, O'Duffy J D, McLeod R A. Deforming arthritis of the hands in polymiositis. Arthritis Rheum 1976; 19: 243-8.

24 Reginato A J, Schumacher H R. Synovial calcification in a patient with collagen-vascular disease: light and electrion microscopic studies. J Rheumatol 1977; 4: 261-71.

25 McCarty D J, Silcox D C, Coe F, et al. Diseases associated with pyrophosphate dihydrate crystal deposition: a controlled study. Am J Med 1974; 56: 704-14.

26 Thompson G R, Ting Y M, Riggs G A, Fenn M E, Denning R H.
Calcific tendinitis and soft-tissue calcification resembling gout JAMA 1968; 203: 464-72.

27 Caner J E Z, Decker J L. Recurrent acute (gouty?) arthritis in chronic renal failure treated with periodic hemodyalisis. Am J Med 1964; 36: 571-82.

28 Ellman M H, Brown N L, Katzenberg C A. Acute pseudogout in chronic renal failure. Arch Intern Med 1979; 139: 795-6.

29 Schumacher H R, Somlyo A P, Tse R L, Maurer K. Arthritis associated with apatite crystals. Ann Intern Med 1977; 87: 411-6.

30 Lichtenstein L, Wayne Scott H, Levin M H. Pathological changes in gout: survey of eleven necropsied cases. Am J Pathol 1956; 32: 871-95.

31 Reginato A J, Schumacher H R, Allan D. Rabinowitz J L. Acute monoarthritis associated with lipid liquid crystals. Arthritis Rheum 1982; 25: S35 (abstr). 